\title{
The Blended Learning Approach and Its Application in Language Teaching
}

\author{
Hanan Tawil, PhD \\ Lebanon
}

\begin{abstract}
The purpose of this paper is to conduct a meta-analysis of the pedagogical practice of blended learning, or the use of both direct instruction and online learning in second language instruction. A thorough review of the relevant literature over the last two decades on blended learning generally, and second language instruction using blended learning techniques in particular, is presented. Demonstrating the positive benefits from applying blended learning in language instruction, the study results should help guide language instructors in understanding the practice and implementation of this approach. The major conclusions of the study are that blending learning enhances the learner's experience of a new language, and offers greater efficiency in the communication and practice of that language. Efficient and user-friendly technology, with direction instruction and practice in a face to face setting, are seen as the key to successful blended learning language instruction.
\end{abstract}

\section{Introduction}

\subsection{Background of the Study}

There is an abundance of recent research on the many challenges to language learning and acquisition. Banditvilai (2016) states that the language learning process is unique and different in every individual. Students also have varied learning styles; some can grasp content quickly while others need time to absorb new material. Launar (2010) feels that the failure to address each student's learning differences may inhibit the learning process. According to Kintu, Zhu, and Kagambe (2017), the best instructors respond to this challenge by embracing different teaching approaches to cater to each student's learning style. The most effective teacher settles on a particular mode of teaching, based on its effectiveness and positive effects on the student's progress. Guzer and Caner (2013) show that blended learning (combined online and brick and mortar instruction) has been increasing since the turn of the century. Various scholars have lauded these recent developments encouraging teachers to adopt blended learning. Moore and Kearsely (2011, p. 92) argue that a cardinal rule for distance learning is that learners and teachers must have the same technology platform and instructional model; they found blended learning to be an effective methodology for the problem of synchronizing teacher and learner.

Lo Bianco (2010) notes that blended learning have now been used in teaching in higher education, secondary, and even in elementary institutions. It has also been adopted in language teaching; Hwa, Weei, and Len (2012) point out that Malaysian university have embraced blended learning for teaching Chinese as a second language. There is a notable rise in the use of blended learning methods for language teaching, as a way of addressing challenges associated with the language learning process. In this context, the present study aims at delineating the exact approach that blended learning serves in language teaching, and argues for its benefits.

\subsection{Blended Learning}

Education systems are constantly changing, with the common reason being the drive to respond to the social, political, and economical challenges that are faced by societies every day (Aguilar, 2012). In this regard, education is a dynamic phenomenon that needs to align with the current trends in society, in order to address the conflicts of multiple technologies. Hwa, Weei, and Len (2012) observe that the current upsurge in the number of new learners stimulates the need for more effective teaching methods, to create an environment conductive to . One of the most notable trends is the computer technology that has revolutionized our school systems. With the increased use of Information Communication Technology (ICT) around the globe, education systems are adapting new technology into the curriculum, to help meet current demands in the education sector (Lo Bianco, 2010).

Aguilar (2012) argues that the alignment of technology with education practices is a positive step that has been triggered by issues such as transportation distances and building costs. 
Neumeier (2005) defined blended learning as the amalgamation of face-to-face (F2F) and computer-assisted learning (CAL) in a single teaching and learning environment. Allen (2010) explains that the term "blended" has been adopted to refer to integrating ICT in two teaching and learning environments. Aguilar (2012) defines blended learning as an integration of traditional face-to-face learning and online learning aided by ICT platforms.

Other scholars, such as Sharma (2010), see blended learning as a system that joins face-to-face classroom teaching with an appropriate use of technology, where technology can refer to a wide variety of components including the internet, interactive whiteboards, and language labs among others. Krause (2007) summarizes all of these definitions and describes blended learning in a detailed analysis, as a setting in teaching and learning environments where there is an effective amalgamation of varied delivery platforms, models of teaching and learning approaches. Blended learning is thus a result of implementing a strategic and systematic approach to the application of technology, combined with the best features of face to face interaction between teachers and students.

Sharma (2010) says the definitions of blended learning indicate that there are at least three requirements; more than one delivery mode, instructor-based training methods that are technologically enabled, and traditional teaching approaches which are interactive, rich in content, and facilitated by a teacher. Lim, Morris and Kupritz (2007) offers a similar model; blended learning can have various combinations of these elements: offline and online learning, live and collaborative learning, structured and unstructured learning, work and learning, and mixing of either synchronous physical formats with online formats or asynchronous physical with online formats. The bottom line remains that blended learning has to use two media of instruction, where one represents the traditional methods used in face-to-face interaction, and the other a technological mode of instructions of relaying information to the learners.

Sharma (2010) concludes his study by arguing that blended learning is a logical response to the development of previous pedagogical tendencies that employed an array of teaching methods, sometimes aided by new technology. In sum, the main requirements for blended learning are diverse teaching methods, physical presence of both teacher and students, elements of control such as time and pace, and at least some instruction mediated through technological platforms for content delivery.

\subsection{Purpose of the Study}

Shea (2007) and Kintu, Zhu, and Kagambe (2017) found that there is a growing body of literature supporting the use of blended learning in higher learning institutions. In a similar vein, scholars have introduced the concept in language teaching as an alternative to the traditional method that was solely based on direct instruction. It is therefore critical to establish an evaluative framework that assesses what blended learning brings to the table for language learning. This study highlights the possibilities offered by blended learning to language teaching, to find what benefits the method brings to language acquisition. In this respect, the findings of this study should help teachers in understanding what exactly to expect from blended learning if they use it as their method of instruction in language learning. In addition, they should learn of the negative outcomes associated with the concept, in order to better inform their decisions.

\subsection{Research Question}

What are the benefits of using a blended learning approach in language teaching?

\subsection{Significance of the Study}

The discoveries made from the study will be instrumental in teacher training, Computer Assisted Language Learning (CALL), and the broad spectrum of blended learning research. This paper looks at various studies that have been channeled towards the area of blended learning and language teaching and siphons the findings and empirical evidence on the outcome of fusing the two elements. This meta-study approach develops models and recommendations for institutional administrators and program directors in preparation of their curriculum in language learning. Language teachers are in the best position to benefit from this study as they will manage to understand the best approach to enhancing acquisition in language learners. New technology developers are also expected to benefit from understanding the improvements they can effect to develop the aspect of blended learning. Ultimately, the study opens a window for further research aimed at developing the field of blended learning and also language teaching. In this respect, the study categorically establishes the possibilities that are created by using blended learning and how it enhances language teaching. 


\section{Literature Review}

\subsection{Introduction}

This review of the literature presents recent research regarding blended learning, from the perspective of the enhancement of language teaching. Banditvilai (2016) asserts that numerous scholars have called attention to this practice and have outlined the possible contributions it makes to language teaching and learning. In that light, this section outlines the main features of blended learning, how blended learning is implemented, and specific outcomes from fusing blended learning methods in language teaching.

\subsection{Blended Learning Features}

Kintu, Zhu, and Kagambe (2017) state that blended learning is constructed under specific features which are the primary foundation for this concept. According to these authors, these features include interactions, technology quality, and face-to-face support. Banditvilai (2016) defines interaction or connectedness in the context of blended learning as coordination and cooperation between teachers and students, and use of a mixed mode of content delivery, which in this case refers to the technology tools found on websites and in language labs. Blended learning as understood from that definition is pedagogy that incorporates an amalgamation of new technology and traditional learning methods.

\subsection{Withdrawal and Disconnectedness}

In this respect, Kintu, Zhu, and Kagambe (2017) cite Willging and Johnson (2009), who feel that lack of interaction leads to withdrawal and disconnection from the teacher and class. The problems of withdrawal, lack of concentration, and student disconnectedness are detrimental to effective learning, as alienated students do not engage with the teacher and do not necessarily grasp what is being taught. Notably, the main issue that brought about the development of blended or hybrid learning was the challenges experienced with the new technology in learning in face-to-face learning as a unit (Moore \&Kearsely, 2011). For technology- mediated learning, Moore and Kearsely (2011) found that the major challenge to e-learning or online supported learning was that students were being left out during the learning process. This may be caused by the factor that the students are fascinated by the technological devices, especially if it is their first experience, rather than paying attention to the class proceedings.

Another reason established by Banditvilai (2016) is that reading academic text from a digital display is quite boring and brings the feeling of loneliness, also leading to withdrawal. Moore and Kearsely (2011) observe that the presence of technology-aided instruction facilities may sometime hinder the connection between teachers and students. These technological devices or platforms may act as a barrier to the cooperation and exchange between learners and teachers, and encourage students to retreat from face-to-face instruction to the now-familiar video screen.

Willging and Johnson (2009) observe that disconnectedness in classroom can deprive learners of the morale to learn, in that it develops feelings of isolation. In fact, it diminishes the propensity of students to learn from each other and to uplift each other's motivation towards learning as a team. Kintu, Zhu, and Kagambe (2017) therefore put a lot of emphasis on the role of interaction as a building block for blended learning. Blended learning diversifies the mode of interactions as stakeholders can interact either face-to-face or through online platforms. The interaction between learners, teachers, and their peers according to Kintu, Zhu, and Kagambe (2017) makes blended learning effective and avoids the challenges of withdrawal and lack of concentration. Teachers are advised on the importance of enhancing connectedness among the three elements of blended learning, teacher, learners, and mode of delivery in order to make learning effective. According to Shraim (2012), the teacher should retain the authority for controlling the amount of time taken interacting with the technological platforms, the place of learning, and the pace of instruction, including aspects such as clarification. This implies that learners should not have absolute control over the technological platforms as this would defeat the purpose of blended learning. Without a locus of control, Shraim (2012) feels that the aspect of interaction can be misused, leading to the failure of blended learning.

Aguilar (2012) also finds it paramount for educators to ask logical questions regarding the issue of "connectedness" in implementation of blended learning. Such questions can include 1) how often teacher-students meet face-to-face as compared to online experiences, 2) what should be accomplished in either one of the learning platforms, and 3) how do these platforms enhance social interactions, among other considerations. 
These questions as posed by Aguilar (2012) have the effect of enhancing the element of control, to ensure that the interactions are not overemphasized at the expense of learning outcomes.

System quality is another design feature discussed by Kintu, Zhu, and Kagambe (2017), as a building block for blended learning. In this case, the authors suggest that the mode of content delivery or the technological mediated platform for instruction issuance should meet a certain threshold for educators to get maximum performance out of them. As observed, technology is a key factor of blended learning systems; it is vital to ensure that the technology used is of high quality, reliable, and it is easy to navigate. Launer (2010) castigates the use of obsolete technology in education, saying that it is bound to yield poor results that will undermine the learning initiatives and fail to meet the learning objectives. Confirming this, Kintu, Zhu, and Kagambe (2017) show that poor technology quality gives less satisfaction to the users, affecting their attitudes and motivation towards blended learning.

According to Osgerby (2013), with the rapid technological advances, users are fully engaged with platforms that are fast, efficient, and reliable; efficient technology yields greater user satisfaction.. Technological quality thus plays a key role in satisfaction, as Shraim (2012) confirms; hence the importance of examining technology quality in order to get the best out of blended learning programs. In the same vein, Willging and Johnson (2009) found that learner satisfaction is paramount for positive learning outcomes such as performance, motivation, satisfaction, and knowledge construction Moving on, face-to-face support is a core feature for blended learning as scholars have noted the importance of interaction in learning. Osgerby (2013) is wary of teachers who tend to lean on one method in hybrid learning programs, purporting that this imbalance does not produce the expected learning outcomes. It is therefore important to enhance technology with face-to-face experience in the classroom setup. Osgerby (2013) further maintains that the face-to-face experience gives the teacher the best opportunity to understand the learners' abilities and inadequacies. From this, the teacher can identify what needs to be done to improve knowledge construction among learners. Face-to-face support also yields more social interaction and sharpens communication skills that are developed within the classroom environment.

Finally, Osgerby notes that learners are more successful if they are in a position to interact with their teachers and peers so that they can make clarifications, exchange ideas, and learn from each other. Face-to-face sessions can be enhanced through other elements such as humor, seeking differing opinions, non-verbal expressions, gestures, and even giving practical examples in class (Osgerby, 2013). The bottom line is that teachers should not hide behind the "technology veil" and resume the traditional role of the lecturer, or on the other hand, rely too heavily on oneway technology. Blended learning calls for the use of both types of delivery interchangeably and exhaustively, to make the best out of all elements and achieve the outlined objectives (Shraim, 2012).

\subsection{Blended Learning and Language Learning}

Various scholars have debated the merits of embracing blended learning in language teaching and learning (Hong \& Samimy, 2010; Neumeier, 2005; Stracke, 2007). Hong and Samimy (2010) confirm that this debate has gained prominence, based on the upsurge in the number of studies focusing on second language teaching since 2000. Most of these studies have concerned blended learning pedagogy and its implementation, while others have looked at the learning outcomes obtained after implementing blended learning. The following section therefore looks at a number of research findings regarding both the implementation and the outcomes of blended learning in language teaching.

\subsection{Implementation of blended learning in language teaching}

Hong and Samimy, (2010); Neumeier, (2005); Stracke, (2007), Saggara and Zapata (2008); and Cartner (2009) all affirm that blended learning can only be effective if students have positive attitudes and a positive technology experience. Basically, this means the first step for embracing blended language in language teaching is ensuring that learners are positive and experienced when it comes to the technology. Saggara and Zapata (2008) looked at the extent to which attitude and experience affected 245 second language learners using blended learning, with Spanish the target language; they found that those who had not used computers previously felt unmotivated towards blended learning, and had a negative attitude regarding their learning outcomes. Attitude was a major factor in concentration and participation in the class work.

Comas-Quinn (2011) asserts that it is impossible to achieve the benefits of blended learning if learners retain a negative attitude in the class. Cartner (2009) remarks on the importance of having an appealing environment to stimulate positive attitudes. 
This was based on Cartner's (2009) study on fusing online courses and classroom instructions for 52 learners of English; positive attitude was linked to the time reduced to learn the language. This is a clear indication that attitude is at the center stage of proper implementation of blended learning. Saggara and Zapata (2008) emphasize that it is paramount for language teachers to cultivate a good attitude toward student-technology interaction as the basis for blended learning.

Based on Hong and Samimy's (2010) findings, teacher training and support is another fundamental need to be considered in creating an effective blended learning in the language teaching process. Teacher training and support simply refers to establishment of programs that give teachers an opportunity to engage with the blended learning components and methods. Coryell and Chlup (2007) found that effective English Language Programs in the United States emphasized the role of instructor professional development in the areas of pedagogy and technology.

According to Hong and Samimy, (2010), teachers must be conversant with the technology-mediated platforms and the learning environment, to produce the best results. Teacher training and support should range from professional development programs in instructional strategies to technical support with computer hardware and software. Coryell and Chlup (2007) agree that teachers may be professionals in their classroom skills, but often need extra support to instill language skills using technology in language labs.

Most researchers (Coryell \& Chlup, 2007; Hong and Samimy, 2010) feel that language teachers need more computer assisted learning (CAL) and technical support from the technical department of their schools. This is because teachers may possess the knowledge of passing language skills on to learners, but are not trained to understand the technicalities of online instruction tools and problems such as computer crashes, network delays and asynchronous instruction. Coryell and Chlup (2007) also found out that teacher support was needed even with cooperation and coordination among administrators, instructors, and IT personnel. The effectiveness of blended learning is highly dependent on closer collaboration among these stakeholders who play crucials role in enabling a positive language learning environment.

Another fundamental variable regarding blended learning efficiency is the students' computer literacy skills. Hong and Samimy (2010) based their study on 244 undergraduate EFL; resultantly, students with high computer skills proficiency were positive about CALL and motivated about blended learning. Coryell and Chlup (2007) confirm these findings in a study that gathered information from 15 instructors and four program directors. It is always necessary for students to possess basic computer skills prior to being initiated in a blended learning course. Banditvilai (2016) confirms that language educators have to ensure that technology and online materials are fully-integrated in the course. Technology should be user friendly, easy to master, and conversant in the users' languages. Teacher training in the new technology should be prioritized in order to ensure that the educators understand the possibilities of blended learning environments for second language teaching.

Additionally, Banditvilai (2016) relates teacher support with their attitude while performing their duties. Positive attitude does not only help the student but also the teachers in their line of duty. Teachers with a positive attitude pay attention to all aspects of blended learning and are effective in enhancing language skills. Teachers need to be intrinsically motivated about the issue of using technology to support traditional media so that they can reap the best benefits of blended learning. Therefore, these are the basic elements that enhance the implementation of blended learning in language teaching.

\subsubsection{Outcomes of blended learning in language teaching}

Different scholars have outlined varied ways in which blended language enhance language teaching based on the findings from their studies. According to Shraim and Khlaif (2010), language teaching is a challenging process, and facilitators prefer a teaching method that usually has the best learning outcomes. In the same context, Wang and colleagues (2009) assert that one of the main advantges created by blended learning is support for different methods of language instruction. The purpose of their study was to ensure that teachers had a clear understanding of what benefits each method contributes in blended learning (Wang et al., 2009). Each teaching approach has different challenges, and Wang et al. (2009) find that blending the online and classroom instruction helps to address the inefficiencies identified in each approach.

Wang and others (2009) believe it essential to blend the two methods for the purpose of creating a more effective learning process. Aborisade (2013) believes that the online platform expands learning materials and improves accessibility for learners as a support to traditional classroom instruction. 
This is an advantage in language teaching, as the students are exposed to varied learning aids (recorded drills, conversation practice) which all contribute to broadening their knowledge. In face-to-face interactions, learners depend on the material given by the teacher, which may not be sufficient for their language acquisition. This deficiency is addressed through blended learning, as students have increased access to their practice material.

Similarly, face-to-face interaction supports technology's role in blended learning by infusing other aspects of learning, such as daily conversation, social networking, and group collaboration that would not be addressed if the teacher used only digital learning approaches (Pape, 2010). Often, online learning only covers a few learning skills, and may not acquaint students with all the language skills needed in daily life. Pape (2010) notes that classroom interaction is essential to effective public speaking. Embracing online learning exclusively can prevent the students from developing such special skills as public speaking.

Face-to-face interactions enhance online learning in this area by creating an environment that supports interaction and enhances speaking skills in the target language (Siew-Enga \& Muuk, 2015). According to Aborisade (2013), the main aim for language learning is to be equipped with the target language skills that will help the learner address real-life situations. Public speaking is one of the fundamental ways of expressing oneself and it is best cultivated in the face-to-face interaction in the classroom. Regular practice is fundamental in all language learning and it is vital for students to interact in the target language.

Secondly, collaboration in the classroom setting is associated with group support for problem-solving skills (Wang et al., 2009). This means that learners will be able to handle a task as a team and thus learn how to maximize their cognitive abilities in problem solving. Moreover, technology-mediated platforms also enhance face-to-face language teaching in development of writing skills. Technology gives learners a platform to practice their writing abilities and receive expert guidance. As opposed to other methods such as task-based learning that concentrate on oral practice alone, blended learning enhances writing skills, reading, and speaking, which are all fundamental to increasing English comprehension and communication (Bijeikiene, Rasinskiene, \& Zutkiens, 2011). It is evident that the key advantage of blended learning is that both face-to-face and technology teaching methods support each other, and address the inadequacies found in either approach alone, so as to achieve the best results in language teaching.

Finally, Shea (2007) asserts that blended learning has six paramount outcomes in language teaching: pedagogical richness, access to knowledge, social interaction, personal agency, cost-effectiveness, and ease of revision. As mentioned by Wang et al. (2009), blended learning is effective in increasing inputs and outcomes. This means that learners have diverse sources for their materials, leading to an increased pool of knowledge. In sum, online and other technological teaching materials enhance ease of revision, due to the accessibility of learning materials. It may also be associated with greater access to learning where the facilitator can manage various learners at ago.

The goal of social interaction has also been addressed, as it responds to the challenges of disorientation and disconnect in the classroom. Precel, Yoram, and Alberton (2009) confirm that reading academic text from a digital display may be problematic, and students' achievements from online reading tend to be lower. Online learning alone creates a possibility of loneliness or social detachment, which are major detractors to language acquisition. But blended learning, according to Precel, Yoram, and Alberton (2009), succeeds by providing an opportunity for combining online and F2F learning experiences which bridge the gap of social detachment. However, Shea (2007) acknowledges something of great interest to language teachers: pedagogical richness.

Pedagogy is broadly defined as the art and practice of direct instructional teaching. Shea (2007) calls pedagogical richness the transition from a presentation format to an active learning format. Chew and Wee (2009) define the concept of pedagogy as a special ability that enables the teacher to integrate, transform, and represent content and knowledge, using approaches that are easy for the learner to comprehend. Pedagogical richness, according to these authors, combines subject matter and content knowledge for greater student understanding. Zhu (2012) further posits that pedagogical richness is instrumental in the teacher's understanding of how particular topics, problems or issues are organized, presented, and adapted to address myriad student abilities and interests. In language teaching, it is important to pinpoint the learner's specific needs to achieve language proficiency.

As reported by Shraim and Khlaif (2010), each student can have a special ability or deficiency when it comes to language learning. It is up to the teacher to pinpoint these abilities and inadequacies and establish the most appropriate ways to respond to them. Blended learning comes in as a facilitator of pedagogical richness in an array of situations. 
First, F2F class experience enhances social interactions where the teacher is able to pinpoint the specific abilities of the student (Siew-Enga \& Muuk, 2015). Thus, F2F instructions allow students to express ideas, interact with others, build speaking skills, and improve cultural understanding of the target language. Second, technology gives the teacher a spotlight on each students individual capabilities, or what Shea (2007) calls personal agency.

In reference to Aborisade (2013), technological platforms engage learners in an individual presentation and it is easy for the teacher to learn about their cognitive skills, thinking patterns, and knowledge constructivism. Chew and Wee (2009) feel that the main impetus of pedagogical richness is that it brings a rendezvous between knowledge representation of subject matter by the teacher, learning difficulties and conceptions among the students. It therefore gives the facilitator an advantage to address these issues for the purpose of enhancing language skills.

Aborisade (2013) asserts that blended learning and pedagogical richness integrate three important teaching dimensions; 1) knowledge constructivism, 2) social constructivism, and 3) problem-based learning. The concept of knowledge construction is construed in the basis that effective learning is achieved when there is active learning (Rahman, Yasin \& Jusoff). Shea (2007) mentioned earlier that pedagogical richness transforms learning from mere presentation to active learning. Blended learning helps learners initiate, discover, and accomplish the procedurals of knowledge construction in the classroom set-up (Bijeikiene, Rasinskiene, \&Zutkiens, 2011). This implies that learners can stimulate their cognitive abilities to create knowledge that has positive outcome in relation to what they are learning. Rahman, Yasin and Jusoff () assert that online discussion prompts learners into the steps given to construct meaning out of the target language through the process of giving and receiving knowledge amongst themselves. Akkoyunlu and Soylu (2008) affirm that the ability to produce knowledge and distribute is initiated by knowledge constructivism.

\subsubsection{Social Interaction}

Social constructivism theory is concerned with how learners interact with each other. It is based on the belief that most people learn as a result of social interaction and collaboration with others. Shraim and Khlaif (2010) argie that the new technology platforms provide an array of socialization spaces where learners can exchange ideas and collaborate in completing a task. This finding has previously been addressed, which suggests that it is a critical benefit of blended learning for language teaching. Lastly, pedagogical richness involves problem-based learning which requires the use of real-world scenarios, social learning and application of knowledge to new situations. In language teaching, Grgurovie (2011) believes it paramount to embrace practice using the authentic materials of the target language. This ensures that learners are in a position to get the exact meaning of words, sentences, and structures in the target language.

Basically, there are some aspects such as sociolinguistics that cannot be taught in a classroom set-up unless the learner immerses into the community or professionals using the language to absorb such meanings. Blended learning has managed to solve this issue by providing an opportunity where the learner can interact directly with practical scenarios using the target language probably through online platforms such as video-conferencing. Problem-based learning is multi-faceted as it imposes both language skills and at the same time enables learners solve real-life scenarios (Poon, 2013). The core purpose of learning a language as observed is to interact and address issues that are facing societies. Traditional learning only provides the basics through a presentation format but lacks the window for interactive learning.

\subsection{Research Methodology}

\subsection{Introduction}

Patton (2002) has defined research methodology as the groundwork and procedural basis for conducting a study by the investigator. Research methodology employs a sequence of stages and levels that are used in obtaining data from the field and using it to respond to the research questions. Research methodology provides an explanation of the techniques applied to collect the data, analysis, and present it in a logical manner (Creswell \& Clark, 2007). Patton (2002) points out that a study failing to collect data from the field would always be incomplete, as it would be unable to analyze the observations made and confirm or reject the hypothesis.

\subsection{Research Philosophy}

According to Creswell and Clark (2007), there are two major research philosophies that are used as guidelines for 
Conducting research. These two philosophies are the interpretivism paradigm and the positivism paradigm (Creswell \& Clark, 2007). The interpretivism paradigm assumes a subjective viewpoint, acknowledging that there are diverse realities that exist from the single or multiple phenomena being investigated. This type of research philosophy is widely used when conducting qualitative research. Patton (2002) defines a qualitative study as research that explains and interprets observations or phenomena without statistical analysis.

The main objective of interpretivism is to respond to the why and how of the stated research questions (Patton, 2002). Positivism, on the other hand, is a research philosophy concerned with quantitative measures or empirical research, and often employs statistical analysis to answer the research questions. Positivism is an objective paradigm that usually focuses on a single aspect or dimensions of the phenomena being studied (Creswell \& Clark, 2007). In this respect, this study is qualitative; hence, it follows the interpretivism paradigm.

\subsection{Analysis and Discussion}

\subsection{Introduction}

This section of Analysis, Discussion, and Conclusion revisits the findings made in literature review and uses them to reach a coherent answer to the research question. There are various findings that can be derived regarding the possibilities drawn from blended learning in language teaching in literature review section. These are outlined as follows.

\subsection{Pedagogy and Language Teaching}

One of the most fundamental conclusions that can be drawn from the literature research conducted in this study is the aspect of pedagogy richness as a result of blended learning. As noted by Goya (2015), pedagogy is the teacher's ability to understand various teaching methods that can be embraced in order to get the maximum learning outcomes in language teaching. Pedagogical richness assumes that the teacher is well conversant with the area of concern, which is the subject matter, and has the ability to transfer that knowledge to the student. Therefore, pedagogical richness is an integral tool for transforming language skills from the teacher to the learners.

Miyazoe and Anderson (2010, p. 186 ) explain that teaching and learning are "two sides of a coin that need to be flipped simultaneously" in order to acquire language skills effectively. The teacher needs to be part of both sides of the coin in that he or she has exemplar skills in teaching and also in helping learners absorb what is being taught. In most cases, teachers may be professionals in their field but lack the ability to make learners construct that knowledge in their mindset. Blended learning therefore solves this inability by instilling pedagogical richness among language teachers.

According to Miyazoe and Anderson (2010), a new language cannot be acquired through presentation only; learners must decipher the teacher's instructions and construct their own usages. The same rule applies in language teaching where students have to contextualize the instructions given in order to benefit from the material. Blended learning gives myriad opportunities for teachers to connect both orally and through technologymediated platforms. As observed above, blended learning embraces technological integration, which means that the facilitators have to infuse digital technologies into their teaching pedagogies.

In language learning, technology is constantly used for information search and social interaction which means that it has to be part of the lesson design. Starkey (2010) insists that teachers using blended learning should have the ability to develop the potential of digital technology and understand that there is a gap between applications and knowledge creation in the digital age. Blended learning comes to the rescue of teachers by giving the ability to create knowledge whilst using technological mediated platforms in language learning. In fact, Starkey (2010) asserts that ICT tools have blossomed and times teachers can be overwhelmed in keeping up with the developments. As a result, pedagogical models drawn from blended learning are integral in enhancing technological mediated teaching.

\subsection{Constructivism and Connectivism}

Grgurovie (2011) outlines two pedagogical theories that are linked with blended learning and which are fundamental in language teaching; constructivism and connectivism. Rahman (2011) asserts that the theory of knowledge constructivism is majorly based on the premise that people learn through the reflection of their own experiences and construct knowledge in the world they live in. 
Grgurovie (2011) insinuates that knowledge constructivism is different from social constructivism since the latter is only concerned with the role of social interactions in knowledge creation while knowledge constructivism model argue that students want experiential reality that is confirmed by others or a person in control. This implies that students want to test their abilities under the supervision of an individual who has more knowledge capacity than them.

As mentioned above, pedagogical richness propagates for professionalism and knowledge capacity among the teachers with the ability to transform the knowledge to the learners. Ideologically, constructivism is based on whether the teacher has the knowledge and if he or she can transfer it to the students (Siew-Enga \& Muuk, 2015). This is why students want someone "in command" to help them fathom the deeper features of the target language they are learning.

Connectivism on the other hand is based on the hypothesis that knowledge is co-created through connections in an open and flexible curriculum. Basically, the teacher is the language expert who facilitates learning, but students participate in co-creating knowledge through expansive use of sources and materials. Blended learning avoids the probability of mono-directional learning, where only one party is providing information and the other acts as dormant recipient. Larsen (2012) mentioned that blended learning transforms instruction from a mere presentation to active learning. Language teaching is much effective when there is participatory learning from all parties (Poon, 2013).

Lastly, pedagogical richness delivered through blended learning also develops problem-based learning. This means that blended learning exposes learners to practical scenarios which are fundamentalfor sharpening their problem solving skills. They can be connected to real-life experiences through the technology platform, and handle the tasks on an individual basis (Siew-Enga \&Muuk, 2015). This ion turn sharpens their cognitive skills, self-confidence, and problem-solving skills. Therefore, pedagogical methods enhanced through blended learning are critical in language teaching, as they help teachers succeed in achieving positive learning outcomes.

\subsection{Blended Learning Supports Other Teaching Methods}

From the introductory part, this study has reflected on the importance of embracing various methods in language teaching, especially those with positive learning outcomes. Comas-Quinn (2011) states that one teaching methods cannot have all the features required to reap all the benefits in language teaching. However, blended learning allows the use of varied methods at the same time; basically, traditional methods fused with technological based methods. A key advantage of fusing the teaching approaches is that they complement each other with the aim of achieving the set objectives. Barnes (2017) observe that each methods used in hybrid learning have their own strengths and weaknesses. The positive thing is that each approach addresses the weaknesses established in the previous one (Poon, 2013). For instance, the largely noted weakness of technological teaching is that it evades the aspect of interaction in the classroom.

As noted from various scholars, interaction is fundamental in language teaching, as it connects teachers and their learners. Lack of interaction is deleterious to learning as it leads to negative outcomes, such as withdrawal, lack of concentration, and a feeling of isolation. Comas-Quinn (2011) suggests that the lack of interaction in a technology platform can best be addressed by face-to-face classroom experiences. On the other hand, face-to-face has limited learning materials and time constraintd for the purposes of language practice. In this case, technology comes in handy as it provides diverse learning materials and resources, so learners can use the platform for revision even in the absence of the teacher (Tayebinik \& Puteh, 2012). In fact, they can connect with the teacher through the platform and seek any further clarification needed.

\subsection{Autonomy and Confidence}

Soliman (2014), in his study on e-learning to develop EFL students, found that it helped them acquire language skills and activate their independent learning. Larsen (2012) also found out that blended learning initiated independence in learning and personal responsibilities, which are essential, tools for language learning. Banditvila (2016) concludes that teachers and learners have a common perception that blended learning help students take responsibility for their own learning, by making them autonomous and confident. Ahmad and Al-Khanjari, Z. (2011) claim that technology platforms leave more space for learners to work individually and interact with people on an online space. Individual working provides skills such as management skills, research and development skills, and more so the intrinsic impetus of learning. 
Again, the intrinsic motivation and requirement for all learning is a positive attitude. Rahman (2011) identified attitude as the main vehicle that drives learners' interests. Banditvila (2016) noted that it is generally difficult to teach language in an unmotivated class with negative attitudes. Instruction becomes tedious and time consuming, and the class may not necessarily achieve the overall learning outcomes. As found by Larsen (2012), blended learning helps students become self-confident, which is the first ingredient of positive attitude toward learning. Banditvila suggests, however, that introverted students may eventually open up and interact freely with the others. According to Banditvila (2016), interaction is important for the acquisition of speaking skills, and teachers may find it challenging teaching introverted students. More motivated learners can acquire study skills such as time management and organizing classwork. Responsible, self-motivated learners are easy to teach and more readily acquire language skills. They also provide the teacher with more time to organize and plan the course work. Eventually, confident students can be left to study individually and enhance their language skills, which in turn should improve ongoing teacher effectiveness.

\subsection{Conclusion}

\subsection{General Findings}

The general finding regarding blended learning in language teaching is that it delivers a number of advantages for language teaching. First, there are traditional didactic or the expository approaches where content consists of textbook, lectures, and guided or facilitated discussion. This expository approach is then fused with active learning, where a student engages in varied exercises that are at a controlled pace and time. Thirdly, blended learning collaborates and integratea with interactive learning. since content is co-created among students who are interacting with the teacher. In blended learning, technology is used to support all the three concepts; traditional didactic, active learning, and interactive learning. As a result, the teacher is exposed to varied approaches that address unique and specific needs of the language learner.

Most importantly, blended learning can bring a larger pool of learning resources and materials, tools that are useful in knowledge expansion. Traditional methods are limited to the brick-and-mortar material pool, which limits students to the teacher's instructions, school library and textbook. Blended learning aids in increasing the knowledge pool and even in reducing the time consumed in language teaching class work. At the same time, it is important to note that blended learning has some fundamental differences that should be addressed before embracing its use in language learning.

\subsection{Advantage of Blended Learning}

First, there are important aspects such as technology or system quality that will affect efficiency, reliablility, and ease of navigation. Second, teachers must be in a position to establish whether the technology provides learner interaction and connectedness. Lastly, the capacity for face-to-face support to complement the technology platform is also fundamental to language teaching. The combination of these features will enhance efficiency by blended learning, which in turn should lead to improved outcomes in language teaching. Therefore, blended learning seems to be an instructional methodology that should be embraced in new language teaching, in order to produce the best knowledge acquisition and language facility among the learners.

\subsection{References}

Aborisade, P. A. (2013). Blended learning in English for academic purposes courses: a Nigerian case study. in B. Tomlinson \& C. Whittaker (eds.), blended learning in English language teaching: course design and implementation. London British Council, UK.

Adas, D., \&Bakir, A. (2013).Writing difficulties and new solutions: Blended Learning as an approach to improve writing abilities. International Journal of Humanities and Social Science, 3(9), 254-266

Aguilar, J. (2012). Blended learning and the language teacher: A literature review. Colombian Applied Linguistics Journal 14 (2), 163-180

Ahmad, N., \& Al-Khanjari, Z. (2011). Effect of Moodle on learning: An Oman perception. International Journal of Digital Information and Wireless Communications (IJDIWC), 1(4), 746-752

Akkoyunlu, B., \&Soylu, M. Y. (2008). A study of student's perceptions in a blended learning environment based on different learning styles. Educational Technology \& Society, 11 (1), 183-193. 
Banditvilai, C. (2016). Enhancing students' language skills through blended learning. The Electronic Journal of e-Learning, 14 (3), 220-229

Barnes, M. (2017).Encouraging communication through the use of social media tools. In Multiculturism and Technology-Enhanced Language Learning, (IGI Global), 1-12.

Bijeikiene, V., Rasinskiene, S., \&Zutkiens, L. (2011). Teachers' attitudes towards the use of blended learning in general English classroom. Studies About Languages, 18, 122-127.

Cartner, H. (2009). Blended learning and the academic word lists.New Zealand Studies in Applied Linguistics, $15(2), 30-40$.

Chew, C. \& Wee, L. (2009). Use of Blended Approach in the Learning of Electromagnetic Induction. Retrieved from: 9

Comas-Quinn, A. (2011). Learning to teach online or learning to become an online teacher: An exploration of teachers' experiences in a blended learning course. ReCALL, 23(3), 218-232.

Coryell, J. E. \&Chlup, D. T. (2007). Implementing e-learning components with adult English language learners: Vital factors and lessons learned. Computer Assisted Language Learning, 20(3), 263-278.

Creswell (2009).Research Design: Qualitative, quantitative, and mixed methods approaches. Los Angeles: Sage Publications

Creswell, J \& Clark, S. (2007). Research Design: Qualitative, Quantitative, and Mixed Methods Approaches. 4th ed. Thousand Oaks, Calif.: Sage Publications

Goyal, E., \&Tambe, S. (2015). Effectiveness of Moodle-enabled blended learning in private Indian Business School teaching NICHE programs. The Online Journal of New Horizons in Education, 5(2), 14-22.

Grgurovie, M. (2011). Blended learning in an ESL Class: A case study. CALICO Journal, 29 (1),100-117.

Hong, K. H. \&Samimy, K. K. (2010). The influence of L2 teachers' use of CALL modes on language learners' reactions to blended learning. CALICO Journal, 27(2), 328-248.

Hwa, S., Weei, P. \& Len, L. (2012).The effects of blended learning approach through an interactive multimedia ebook on students' achievement in learning Chinese as a second language at tertiary level. International Journal of Computer-Assisted Language Learning and Teaching, 2(1), 35-50,

Kintu, M. , Zhu, C., \& Kagambe, E. (2017).Blended learning effectiveness: the relationship between student characteristics, design features and outcomes. International Journal of Educational Technology in Higher Education. 14(7), https://doi.org/10.1186/s41239-017-0043-4

Larsen, L. J. (2012) Teacher and student perspectives on a blended learning intensive English program writing course, Graduate Thesis and DissertationAmes:Iowa State University.

Launer, R. (2010) 'Five assumptions on blended learning: What is important to make blended learning a successful concept?', Hybrid Learning Lecture Notes in Computer Science. 6248: 9-15

Lei, J. (2010). Quantity versus quality: A new approach to examine the relationship between technology use and student outcomes. British Journal of Educational Technology, 41(3), 455-472.

Lim, D. H., \& Morris, M. L. (2009). Learner and instructional factors influencing learner outcomes within a blended learning environment. Educational Technology \& Society, 12(4), 282-293

Lo Bianco, J. (2010). Language policy and planning.In. N.H. Hornberger\& S.L. McKay (Eds.), Sociolinguistics and language education (pp. 143-174).

McLachlan, C. J., \& Garcia, R. J. (2015). Philosophy in practice? Doctoral struggles with ontology and subjectivity in qualitative interviewing. Management Learning, 46(2), 195-210.

Miyazoe, T., \& Anderson, T. (2010). Learning outcomes and students' perceptions of online writing: Simultaneous implementation of forum, blog, and wiki in an EFL blended learning setting.System, 38(2), 185-199.

Moore, M., G., \&Kearsley, G. (2011).Distance education: A systems view of online learning . (3rd ed.).Wadsworth: Cengage Learning, (Chapter 2).

Neumeier, P. (2005). A closer look at blended learning: Parameters for designing a blended learning environment for language teaching and learning. ReCALL 17(2), 163-178.

Osgerby, J. (2013). Students' perceptions of the introduction of a blended learning environment: An exploratory case study. Accounting Education, 22(1), 85-99.

Patton, M. (2002). Qualitative research and evaluation methods. Thousand Oaks, CA: Sage Publications. 
Pape, L. (2010). Blended Teaching and Learning. American Association of School Administrators. Retrieved November 3, 2017 from http://facultycenter.ischool.syr.edu/files/2012/02/blended-learning-andteaching.pdf

Poon, J. (2013) Blended learning: An institutional approach for enhancing students' learning experiences, Journal of Online Learning and Teaching. 9 (2). 271-288.

Rahman, S. et al, (2011).Knowledge construction process in online learning. Middle East Journal of Scientific Research, 8(2), 488-492.

Sagarra, N. \& Zapata, G. C. (2008).Blending classroom instruction with online homework: A study of student perceptions of computer-assisted L2 learning.ReCALL, 20(2), 208- 224.

Sharma, P. (2010). Blended learning. ELT Journal, 64(4), 456-458

Shea, P. (2007). Towards a conceptual framework for learning in blended environments. In A. G. Picciano\& C. D. Dziuban (Eds.), Blended learning: Research perspectives (pp. 19-36). Needham, MA: Sloan Consortium

Shraim, K., \& Khlaif, Z. N. (2010). An e-learning approach to secondary education in Palestine: opportunities and challenges. Information Technology for Development, 16(3), 159-173.

Shraim, K. (2012). Moving towards e-learning paradigm: Readiness of higher education instructors in Palestine. International Journal on E-Learning, 11(4), 441-463.

Siew-Enga, L. \&Muuk, M. (2015). Blended learning in teaching secondary schools' English: A preparation for tertiary science education in Malaysia. Procedia - Social and Behavioral Sciences 167, 293 - 300.

Soliman, N. (2014) Using e-learning to develop EFL students' language skills and activate their independent learning, Creative Education 5, 752-757.

Starkey, L. (2010). Teachers' pedagogical reasoning and action in the digital age.Teachers and Teaching, 16(2), 233-244.

Stracke, E. (2007). A road to understanding: A qualitative study into why learners drop out of a blended language learning (BLL) environment. ReCALL, 19(1), 57-78.

Tayebinik,M., \&Puteh, M. (2012). Blended learning or e-learning? IMACST, 3(1), 103-110

Wang, M., Shen, R., Novak, D., Xioayan P. (2009). The impact of mobile learning on students' learning behaviors and performance: Report from a large blended classroom. British Journal of Educational Technology, 40(4), 673-695

Willging, P. A., \& Johnson, S. D. (2009).Factors that influence students' decision to drop-out of online courses. Journal of Asynchronous Learning Networks, 13(3), 115-127.

Zhu, C. (2012). Student satisfaction, performance and knowledge construction in online collaborative learning. Educational Technology \& Society, 15(1), 127-137 